\title{
Revisitando o debate sobre o público e o privado em educação: da dicotomia à complexidade das políticas públicas
}

Sofia Viseu*

\section{Resumo}

O debate sobre o público e o privado tem ganho crescente protagonismo na agenda educativa internacional e em diversos fóruns científicos, políticos e sociais. Este artigo visa revisitar este debate, identificando tendências atuais das medidas políticas que tendem para a introdução de uma lógica de mercado nos sistemas educativos. Através do olhar das políticas e da administração educacional, o texto recorre a evidências empíricas disponíveis que mostram os efeitos perversos, particularmente no domínio das desigualdades escolares, que têm resultado da aposta de uma administração centralizada, assim como da introdução de lógicas de mercado e de liberalização da educação. Este fenómeno será interpretado como um indicador da complexidade que reveste as políticas públicas e, nesse sentido, questiona-se a vantagem em manter uma certa dicotomização público/ privado que tende a ignorar resultados não esperados na ação coletiva.

Palavras-chave: Público e privado em educação. Escola pública. Políticas públicas de educação.

\section{Introdução}

O debate sobre o público e o privado em educação tem ganho crescente protagonismo na agenda educativa internacional e em diversos fóruns políticos, sociais e científicos. Refiro-me, em particular, à discussão sobre políticas públicas que visam a construção de mercados educativos e a privatização da escola pública.

Em Portugal, este debate tem estado particularmente ativo, o que decorre, em parte, da publicação de legislação ${ }^{1}$ que pretende alargar e consagrar a liberdade

Professora auxiliar do Instituto de Educação da Universidade de Lisboa; Unidade de Investigação e Desenvolvimento em Educação e Formação. E-mail: sviseu@ie.ulisboa.pt

1 Ver, por exemplo, o Despacho no 5106-A/2012 de 12 de abril de 2012, que define as normas sobre a distribuição dos alunos na rede escolar e o Decreto-Lei n. ${ }^{\circ}$ 152/2013 de 4 de novembro de 2013, que aprova o estatuto do ensino particular e cooperativo de nível não superior. 
de escolha da escola, pública ou privada, por parte dos alunos e suas famílias (MAGALHÃES, 2013)2. Estas iniciativas governamentais têm vindo a gerar alguma controvérsia, o que é visível, designadamente, pela presença regular na comunicação social de opinion makers, especialistas de diferentes áreas, sindicatos de professores, representantes de associações de pais e movimentos de cidadãos, entre outros, esgrimido posições diferenciadas sobre o papel que consideram que o Estado deve assumir na gestão da educação.

Destaco uma entrevista a David Osborne, autor de reforma do Estado norteamericano na era Bill Clinton, publicada num jornal semanário de referência em Portugal, onde se referia à gestão da escola pública nos seguintes termos: "o sistema é muito centralizado, os diretores das escolas não podem contratar ou despedir quem querem e não podem controlar o orçamento. Como é possível gerir uma escola assim?". Aludindo à experiência de Nova Orleães e ao investimento federal realizado após o furação "Katrina", o mesmo especialista defendia as vantagens de sistemas descentralizados e de contratualização com escolas públicas:

As escolas têm cinco anos para apresentarem resultados ou fecham. Ora os resultados escolares já melhoraram e as escolas são geridas de forma independente. A escolha fundamental é se a gestão escolar é feita para professores ou para estudantes. (OSBORNE, 2013).

Se a visibilidade mediática sobre o papel do Estado na gestão do sistema de ensino globalmente é positiva, pelo apelo à reflexão sobre a escola pública, continua a reinar "uma visão maniqueísta" no debate sobre o público e o privado em educação, acentuando-se a polarização entre aqueles que são a favor da escola pública e aqueles que são contra (BARROSO; VISEU, 2003). Este texto visa revisitar este debate, identificando tendências das atuais políticas públicas de educação que apelam para a introdução de mercados educativos e recorrendo a evidências empíricas disponíveis sobre os resultados que estas políticas produzem. Entendendo as políticas numa perspetiva de ação pública, procurarei mostrar que a dicotomização entre público e privado empobrece o debate porque não atende à complexidade da realidade social e ao caráter multirregulado das políticas públicas (COMMAILLE, 2006).

2 Note-se que, em Portugal, este debate está presente na agenda científica desde finais da década de 1990 [ver, por exemplo, Afonso (1997); Estêvão, (1998); Pacheco (2000); Lima; Afonso (2002)]. 
O texto está organizado em três partes. Numa primeira parte, procurarei situar o debate sobre o público e o privado em educação no plano das tendências das políticas de educação mais recentes em Portugal e na Europa. Numa segunda parte, evocarei alguns dos desafios concetuais que esta temática inscreve na agenda científica. Finalmente, na terceira parte, procurarei retirar consequências que estes desafios colocam para o debate entre o público e o privado, considerando a complexidade das políticas públicas.

Tendências nas políticas públicas de educação no debate sobre público e privado O debate sobre o público e o privado em educação não se trata nem de um debate recente, nem uma especificidade portuguesa, nem tão pouco uma questão exclusiva das políticas sectoriais de educação. Deve, por isso, ser contextualizado num contexto mais amplo.

De facto, o debate sobre a introdução lógica de mercado nos sistemas de ensino foi definitivamente introduzido na agenda educativa no final dos anos 1980, com a implementação do Education Reform Act, no Reino Unido, que generalizou a livre escolha da escola pública por parte dos pais, assim como pela introdução do "chequeensino" em alguns estados dos Estados Unidos da América, nos anos 1990 (BALL, 1993). O interesse atual sobre esta temática justifica-se, em parte, pelas evoluções mais recentes das políticas educativas na Europa, designadamente pela adoção de políticas que retomam e adotam, em diferentes graus de intensidade e complexidade, a livre escolha da escola, os "cheques-ensino" e, enfim, outras medidas que visam à privatização da escola pública (DRONKERS, FELOUZIS; VAN ZANTEN, 2010).

Note-se, contudo, que estas medidas políticas remontam a um processo de reconfiguração do papel tradicional do Estado, que ocorre na generalidade dos países europeus. Esta reconfiguração decorreu, em parte, da crise económica mundial do final dos anos 1970 e à designada crise do "Estado-Providência", e tem vindo a acentuar-se no contexto nas mudanças estruturais dos novos modos de governo. Para além da dimensão econômica, esta "crise" também se caracterizou por uma dimensão política no sentido em que revelou uma crescente dificuldade das autoridades públicas em gerir os bens públicos de forma "eficiente e eficaz" (DRAELANTS; MAROY, 2007).

Assim, em primeiro lugar, esta reconfiguração tem servido como tentativa de renovar a legitimidade da ação do Estado por, concetualmente, aproximar governantes de governados, tal como refere Dutercq (2006), 
O Estado deixou de ser o garante dos princípios de igualdade e liberdade. ( ) As instâncias desconcentradas e descentralizadas herdam a delegação e transferência direta da gestão e da regulação, enquanto o Estado mantém todos aspetos relativos à liberdade formal. (DUTERCQ, 2006, p. 1).

Em segundo lugar, esta reconfiguração conduziu à introdução de lógicas de mercado nos serviços públicos. Neste processo, os tradicionais modos de regulação baseados na autoridade formal, normativa e legisladora vão sendo substituídos, progressivamente, por outros modos de regulação, também designados por pósburocráticos, que assentam em políticas constitutivas, tendencialmente mais indiretas e de controlo da ação a posteriori (HASSENTEUFEL, 2008). Estas medidas representam uma "retração da regulação dita burocrática" (baseada no exercício do poder pela autoridade, na hierarquia e na regulamentação formal) para uma "regulação de tipo mercantil" (apoiada no exercício do poder pela influência e o ajustamento mútuo)" (AFONSO, 2003, p. 52).

Neste enquadramento, emergem novos instrumentos de regulação, entre os quais se encontram a contratualização e os prémios; as boas práticas, que descrevem sob a forma de prescrição ou orientação o procedimento adequado; as estatísticas e os novos instrumentos de gestão que fornecem uma medição automatizada de dados quantitativos; e, por fim, a avaliação de indivíduos, objetos, práticas e organizações. De resto, a avaliação constitui um instrumento de regulação central nas políticas públicas da atualidade, designadamente na prestação de contas (FERNANDES, 2013). A avaliação concorre para a construção de indicadores, escalas e classificações (DEMAILLY, 2011) e serve, quer no domínio da autoavaliação, quer no domínio externo, como uma lógica de mercado e orientação para o utilizador ou consumidor (MAROY; DEMAILLY, 2004).

Estes processos de reconfiguração do papel tradicional do Estado, e a circulação à escala transnacional da intensificação destes novos instrumentos de regulação, configuram efeitos de contaminação e empréstimo de políticas (DOLOWITZ; MARCH, 2000) e justificam, em parte, a implementação, ainda que de modo diversificado na sua intensidade e quantidade, de medidas como a criação de mecanismos de contratualização e as charter schools; o financiamento direto às famílias ("cheque-ensino"); a consagração da livre escolha da escola por parte de alunos e suas famílias; a avaliação e publicitação do desempenho das escolas; e, 
por fim, o reforço da sua autonomia das escolas. A combinação mais ou menos articulada destas medidas conduz a políticas que visam à construção de mercados educativos (BARROSO; VISEU, 2003).

\section{0 público e o privado na educação na agenda científica}

Nos últimos anos, a agenda científica europeia tem conferido uma atenção considerável à emergência e à consolidação de medidas políticas que conduzem à construção de mercados educativos (VAN ZANTEN, KOSUNEN, 2013). Trata-se de uma temática que merece a atenção de várias áreas de investigação e apela a contributos teóricos de diferentes tradições de pesquisa (FELOUZIS; MAROY; VAN ZANTEN et al., 2013). A título de exemplo, destaco a economia, preferencialmente mais centrada nas dimensões relacionadas com o financiamento do sistema público, assim como processos de concorrência entre escolas; a sociologia, interessada em compreender a produção de desigualdades sociais ou as dinâmicas de interdependência entre escolas; os estudos de políticas públicas, que elegem a análise das opções políticas em causa; e a geografia, concentrada em questões relativas ao planejamento e gestão da rede escolar.

Se a inscrição do tema "público e do privado em educação" na agenda científica parece certa, ela encerra desafios conceptuais assináveis, sendo de destacar três fatores concorrentes para esse fenómeno: (i) o caráter ideológico que marca o tema "público e o privado em educação"; (ii) a diversidade de problemas e soluções encontradas às escalas nacionais para a implementação de medidas convergentes com a criação de mercados educativos; (iii) a existência de estudos que mostram os resultados contraditórios que estas medidas produzem.

Em primeiro lugar, o debate sobre o público e o privado em educação permanece fortemente ideológico. Como se interrogava Barroso e Viseu (2003), a questão reside no entendimento que se atribui à educação: deve ser entendida como um "bem essencialmente público", onde se justifica uma forte intervenção do Estado que assegure condições de igualdade do serviço público de educação, ou um "bem essencialmente privado", permitindo-se o funcionamento de um "quase mercado educativo, baseado na concorrência e autonomia dos prestadores de serviço (BARROSO; VISEU, 2003, p. 89-90)? Pese embora as diferentes gradações na resposta a esta questão, o mesmo autor chama a atenção para o facto de o debate tender a sublinhar mais o que distingue estas duas posições do que os une. 
De facto, os defensores da construção de mercados educativos ora sublinham que a livre escolha constitui um direto parental (WHITTY, 1996), ora que a competição entre escolas irá desencadear processos de melhoria do seu funcionamento para que possam manter e captar mais alunos (FRIEDMAN, 1997). A defesa desta perspetiva tende a enfatizar o diploma ou certificação como o produto da educação, constituindo um bem posicional e de troca (DALE, 1994).

Já os críticos à construção destes mercados advertem que a "escola poderá tornar-se apenas um instrumento do mercado" (PEREIRA, 2008, p. 337), e a introdução de lógicas de mercado nos sistemas de ensino pode conduzir a uma maior estratificação social, pondo em causa o direito de acesso, em condições de igualdade, ao sistema de ensino (DUMAY; DUPRIEZ, 2013). No mesmo sentido, Ball (2004) refere que a construção de um "sistema educacional comercializado, performativo", tende a apagar os valores éticos da educação, a ignorar "as especificidades das interações humanas envolvidas no ensino e na aprendizagem" e, consequentemente, a reduzir a educação a "processos de produção e de fornecimento que devem cumprir os objetivos de mercado de transferência eficiente e de controle de qualidade". (BALL, 2004, p. 1117). Sobre esta questão, Maroy, Felouzis e Van Zanten (2013) evocam que a educação não poderá ser considerada um bem de mercado, porque se trata, sobretudo, de um trabalho relacional comum, pouco compatível com a ideia de serviço entre prestador e beneficiário. E, a este propósito, vale a pena evocar ideários pedagógicos que entendem que, pelo projeto da educação pública, passa a aceção da criança como um "ator social produtivo", que deve ser dotado de condições de participação e mobilização para a definição do trabalho educativo (SARMENTO, 2004, p. 47).

Em segundo lugar, e na sequência destas diferentes tradições políticas sobre o entendimento do papel do Estado na gestão dos sistemas educativos, a agenda científica depara-se com uma diversidade assinável de opções nacionais, e até mesmo regionais, que visam à construção de mercados educativos: entre situações de livre concorrência entre escolas públicas e privadas, cenários de quase mercados ou de mercados informais; entre a liberalização da escolha entre escolas públicas ou entre as escolas públicas e privadas, etc. (MÜLLER, 2011). A multiplicidade de cenários e a geométrica variável do tríptico composto pelas políticas escolares, a escolha da escola e as estratégias das escolas (FELOUZIS, 2011) aconselha prudência nas comparações e na extrapolação de problemas, soluções e consequências de cada uma das medidas políticas nesta matéria, quer no plano da agenda científica quer no plano da decisão política. 
Finalmente, em terceiro lugar, é possível encontrar uma multiplicidade de estudos e relatórios que circulam a escala transnacional e que apontam para resultados contraditórios sobre os efeitos que as medidas que visam à construção de mercados educativos produzem (LINICK, 2014).

No que se refere a sistemas de ensino onde, por exemplo, a livre escolha da escola ou o cheque-ensino estão em prática há, pelo menos, uma década, merece uma referência especial um dos trabalhos eventualmente mais polémicos e mediatizados dos anos 2000, da autoria de Diane Ravitch, designado The Death and Life of the Great American School System: How Testing and Choice Are Undermining Education. Esta prestigiada investigadora na área da História da Educação desempenhou cargos de conselheira do secretário de Estado para a educação durante a administração de George W. Bush no início da década de noventa. Nessa altura, Ravitch foi defensora do Programa No child left behind onde, entre outros, se incluíam medidas de privatização das escolas públicas, e se previa a contratualização de objetivos mensuráveis para as escolas com o objetivo de melhorar os seus resultados sob pena de encerramento. Passada quase uma década, a autora concluía que se encontrava numa "crise intelectual" (RAVITCH, 2010, p. 1), e que tinha motivos para ter mudado a sua perspetiva quanto ao potencial da avaliação, da prestação de contas e da livre escolha na melhoria do sistema de ensino norte-americano. Mais recentemente, a mesma autora sustenta que a privatização do ensino é uma medida desadequada, apresentando dados que apontam para um aumento das desigualdades escolares, argumentando que:

As escolas estão em crise graças a ataques persistentes e orquestrados que lhe são dirigidos (...) e que ferem os princípios básicos da responsabilidade pública da educação. Estes ataques criam um falso sentimento de crise e servem os interesses de quem quer privatizar as escolas. (RAVITCH, 2013, p. 1).

No mesmo sentido, um relatório publicado em 2007 pela OCDE referia que "a maior liberdade de escolha da escola está associada a maiores diferenças na composição social dos públicos escolares", apresentando uma correlação elevada entre liberdade de escolha da escola e segregação escolar (OECD, 2007). Contudo, ainda reportando-me ao contexto norte-americano, e ao invés de afirmar que as desigualdades se acentuam, outros estudos têm vindo a mostrar 
poucas diferenças entre os resultados escolares de alunos que frequentam escolas públicas e escolas privadas ou com contratualização (WHITTY; POWER, 2002; BENVENISTE, CARNOY, ROTHSTEIN, 2003; HANUSHEK et al., 2007; FIGLIO, STONE, 2012).

No que diz respeito a sistemas educativos tradicionalmente mais centralizados e onde ainda não estão estabelecidos mercados educativos, também dispomos de evidências empíricas sobre a existência de mecanismos de segregação escolar e social.

A título de exemplo, evoco estudos que têm dado conta do sentido estratégico das famílias na escolha das escolas, designadamente das mais escolarizadas e com maior capital social que tendem a fazer escolhas mais informadas (BALL, 2003). Mesmo nos países onde, do ponto de vista do enquadramento jurídico normativo, ainda não existe a livre escolha das escolas, a investigação revelou processos de polarização social, e consequente possibilidade de aumento da desigualdade escolar, graças a mecanismos de estabelecimento de processos de escolha informal da escola (POUPEAU, 2008). Refiro, ainda, um trabalho que visava refletir sobre a emergência de lógicas de mercado na regulação da oferta educativa, apesar da existência de uma "carta escolar", um dispositivo legal que determina a obrigatoriedade da frequência de uma determinada escola em função da residência dos alunos ou local de trabalho dos pais. Os resultados permitiram proceder a um ensaio de hierarquização das escolas em função da posição relativa que ocupam num mesmo espaço de interdependência/ concorrência através da análise dos processos informais de "escolha da escola" pelos alunos e suas famílias (BARROSO; VISEU, 2006).

Parece, assim, que os dados relevam para o facto da escolha da escola ser um fenómeno transversal em vários sistemas educativos, e que existe a montante do enquadramento jurídico-normativo (MÜLLER, 2011), donde as preocupações em assegurar condições de igualdade no acesso, subjacentes à existência de uma centralização dos critérios de escolha, como a "carta escolar", não se concretizam efetivamente.

Uma importante conclusão a retirar da multiplicidade de estudos que apontam para resultados diversificados consiste na ideia que nem as políticas que visam a construção de mercados educativos, nem aquelas que se baseiam numa provisão e administração centralizada dos sistemas de ensino, parecem impedir processos de segregação e desigualdades escolares. Sobre este tema, prevalece ainda incerteza e ambiguidade sobre se as políticas que visam a construção de mercados 
educativos têm vindo a cumprir as suas promessas, ou se, pelo contrário, tem vindo a aumentar fenómenos de desigualdade e segregação social (BUNAR, 2010). O desafio que se coloca à agenda científica é perceber o que justifica estes resultados contraditórios e compreender como pode ser pensado aquilo a que Demo (2007) designou de "imbróglios educacionais".

Uma primeira resposta para esta questão poderá ser de ordem metodológica, sendo que o desafio reside na possibilidade em encontrar dispositivos que permitam estudar os efeitos de diferentes mecanismos de escolha da escola na melhoria da escola pública. De facto, um dos argumentos mais frequentemente utilizados para a defesa da "livre escolha" consiste na possibilidade dessa escolha induzir as escolas a serem mais responsáveis pelos resultados escolares e, como consequência, aumentar a excelência do serviço público. No entanto, os dispositivos metodológicos ainda não se mostram suficientemente capazes de demostrem esta relação, pese embora esforços relevantes na procura de introduzir modelos empíricos que o façam (HATFIELD, KOJIMA, NARITA, 2011).

Uma segunda resposta a esta questão consiste em compreender que estes resultados contraditórios não derivam só de opções metodologias mas decorrem do caráter compósito das políticas públicas, tal como procurarei demonstrar no ponto seguinte.

\section{0 debate entre o público e o privado e a complexidade das políticas públicas}

Numa obra recente, Felouzis, Maroy e Van Zanten (2013) perguntavam se, afinal, os mercados educativos potenciam e produzem mais liberdade no ensino e se tornam mais inovadores, ou se, pelo contrário, tendem a criar mais segregação escolar. Através do estudo desses mercados em ação ao longo do tempo, os autores mostram que os efeitos desse modo de coordenação variam de acordo com a interação dos quadros nacionais e os dispositivos locais. Parece, pois, ser a natureza do contexto de cada país que permite explicar as diferenças e, mais precisamente, a natureza das interdependências competitivas entre escolas (DUMAY; DUPRIEZ; MAROY, 2011). Atendendo a essa constatação, defendo que o facto de estudos apontarem, simultaneamente, para virtudes ou efeitos perversos na introdução de medidas como a livre escolha ou o cheque ensino não se justifica, apenas, pelo recurso a diferentes metodologias, mas constitui um importante indicador da complexidade das políticas públicas. Esta posição decorre da conceptualização das políticas numa perspetiva de 
ação pública, segundo a qual o Estado não é a única fonte de regulação dos sistemas educativos, sendo necessário o estudo da interação de dispositivos reguladores, ou antes, do estudo do Estado em interação (HASSENTEUFEL, 1995). Note-se ainda que, numa tentativa em reforçar a capacidade de controle da ação pública por parte do Estado, assistimos à introdução de instrumentos de regulação de tipo "mercantil" no setor público que se cruza com práticas burocráticas já estabelecidas. Nesse sentido, a variedade de autores e estratégias do jogo social conduzem a um efeito de hibridismo nas políticas públicas "enquanto sobreposição ou mestiçagem de diferentes lógicas, discursos e práticas na definição e ação políticas, o que reforça o seu caráter ambíguo e compósito" (BARROSO, 2006, p. 53).

Justifica-se, assim, o questionamento das vantagens em manter uma certa dicotomização entre público/privado ou, como referiam Le Gales e Scott (2008), a oposição clássica entre "regulação do mercado" e "regulação do Estado". Não se trata unicamente de reconhecer que "a distinção público-privado [é] absolutamente inadequada para captar as complexidades das mudanças a que os sistemas educativos estão a ser submetidos" (DALE, 1994, p. 110). Trata-se, também, de compreender que, esta dicotomização tende a ignorar resultados não esperados na ação coletiva pela coexistência feixes regulatórios, por vezes contraditórios, provenientes de múltiplos atores em diversas instâncias de decisão. Como refere BALL (2013),

As políticas são contestadas, interpretadas e decretadas numa variedade de arenas de práticas, retóricas e textos e as intenções dos decisores políticos nem sempre traduzem diretamente e de forma óbvia as práticas institucionais. (BALL, 2013, p. 9).

Desta orientação conceptual, é possível retirar uma consequência central para o debate entre o público e o privado em educação e que consiste no reconhecimento da importância dos contextos locais onde também se jogam as políticas públicas. Mesmo perante efeitos de transferência e empréstimo (DOLOWITZ; MARCH, 2000), as políticas que visam a construção de mercados educativos que circulam à escala transnacional e que são adotadas em contextos nacionais, agem em contextos particulares, ideologias e estruturas já existentes. Este processo traduz bem os fenómenos de regulação autónoma, local e situacional que descreve Reynaud (2003), e que se referem ao modo como os atores sociais recebem e se (re)ajustam aos mecanismos e aos conteúdos de sentido que caracterizam a regulação de controlo de acordo com os seus interesses. 
Ora, o reconhecimento da importância dos contextos locais e da autonomia na gestão da escolar, onde se recebem e produzem políticas educativas, constitui uma dimensão reconhecida como central quer pelos defensores quer pelos opositores da construção dos mercados educativos (muito embora para os primeiros represente um mecanismo de obtenção de vantagens competitivas, e para os segundos se afirme pela necessidade de aumentar o distanciamento em relação à administração central). Parece necessário que o debate não se centre tanto naquilo que distingue público e privado, mas mais no que os une, e que passa precisamente pela valorização da gestão local da escola, designadamente pela aposta em "novas modalidades de regulação e de intervenção que permitam a recriação da escola como espaço público de decisão coletiva". (BARROSO, 2005, p. 746).

Como refere Canário (2007), o monopólio educativo conquistado pela escola pública acabou por contribuir para que se fechasse sobre si mesma ao invés de desenvolver uma:

Ação educativa globalizada ( ) dentro do próprio estabelecimento de ensino e promovendo uma multiplicidade diversa de oportunidades de aprendizagem; ( ) com uma conexão privilegiada entre estabelecimentos de enino de uma mesma área criando modalidades de colaboração ( ) no quadro de um território e ( ) de desenvolvimento local integrado. (CANÁRIO, 2007, p. 20).

Para concluir, recupero as palavras de António Nóvoa, para se referir à defesa de um "espaço público da educação", que implique o aumento do

compromisso social com a educação, acolhendo e apoiando iniciativas de famílias, de associações, de poderes locais ou de professores, que se desenvolvam num quadro de abertura e de integração de todas as crianças. (NÓVOA, 2002, p. 238).

Demonstrada a complexidade das políticas públicas que, pela presença de múltiplos atores e autores, torna-se difícil, senão impossível, a definição do que melhor funciona "o público ou o privado". Por isso, a dicotomia pode ser ultrapassada pelo envolvimento, participação e exercício da cidadania dos atores escolares na definição do interesse comum, cabendo ao Estado a garantia de condições de equidade e coesão social. 


\section{Referências}

AFONSO, A. J. O neoliberalismo educacional mitigado numa década de governação social-democrata: um contributo sociológico para pensar a reforma educativa em Portugal (1985-1995). Revista Portuguesa de Educação, v. 10, n. 2, p. 103-137, 1997.

AFONSO, N. A regulação da educação na Europa: do Estado educador ao controlo social da escola pública. In: BARROSO, J. (Org.). A escola pública - regulação, desregulação privatização. Porto: Asa, 2003, p. 49-78.

BALL, S. Education Markets, Choice and Social Class: the market as a class strategy in the UK and the USA. British Journal of Sociology of Education, [S.1.], n. 14, v. 1, p. 3-19, 1993.

.Class Strategies and the Education Market: the middle classes and social advantage. London: Routledge Falmer, 2003.

. Performatividade, privatização e o pós-Estado do Bem-Estar. Educ. Soc, [S. 1.], v. 25, n. 89, p. 1105-1126, 2004.

. The education debate. Bristol: The Policy Press, 2013.

BARROSO, J. O estado, a educação e a regulação das políticas públicas. Educ. Soc., [S. 1.], v. 26, n. 92, p. 725-751, 2005.

. A Escola Pública: regulação, desregulação, privatização. Porto: Edições ASA, 2006.

BARROSO, J.; VISEU, S. A emergência de um mercado educativo no planejamento da rede escolar: de uma regulação pela oferta a uma regulação pela procura. Educ. Soc., [S. 1.], v. 24, n. 84, p. 897-921, 2003.

. De la régulation par 1 offre scolaire à la régulation par la demande: le cas de Lisbonne. Revue française de pédagogie, [S.1.], n. 156, p. 51-61, 2006.

BENVENISTE, L.; CARNOY, M.; ROTHSTEIN, R. All Else Equal: are public and private schools different?. New York: Routledge, 2003. 
BUNAR, N. Choosing for quality or inequality: current perspectives on the implementation of school choice policy in Sweden. Journal of Education Policy, [S. 1.], n. 25, v. 1, p. 1-18, 2010.

CANÁRIO, R. A escola tem futuro? Porto Alegre: Artmed, 2007.

COMMAILLE, J. Sociologie de l'action publique. In: BOUSSAGUET, L. ; JACQUOT, S. ; RAVINET, P. (Org.). Dictionnaire des politiques publiques. Paris: Science Po, 2006. p. 415-423.

DALE, R. A promoção do mercado educacional e a polarização da educação. Educação, Sociedade e Culturas, [S. 1.], n. 2 p. 109-139, 1994.

DEMAILLY, L. Les modes de régulation de la société, les instruments de l'action publique et les régimes de connaissance, 2011. Disponível em: $<$ http://www.knowandpol.eu/Les-modes-de-regulation-de-la.html $>$. Acesso em: 6 jan. 2012.

DEMO, P. Escola pública e escola particular: semelhanças de dois imbróglios educacionais. Ensaio: Avaliação e Políticas Públicas em Educação, Rio de Janeiro, n. 15 , v. 55, p. 181-206, 2007.

DOLOWITZ, D.; MARCH, D. Learning from Abroad: the role of policy transfer in contemporary policy-making. Governance: An International Journal of Policy and Administration, [S. 1.], n. 1, v. 13, p. 5-24, 2000.

DRAELANTS, H.; MAROY, C. A survey of public policy analysis. 2007. Disponível em $<$ http://www.knowandpol.eu/fileadmin/KaP/content/Scientific reports/Literature_review/Draelants_maroy_EN.pdf $>$.Acesso em: 20 dez. 2007.

DRONKERS, J.; FELOUZIS, G.; VAN ZANTEN, A. Education markets and school choice. Educational Research and Evaluation, [S. 1.], n. 16, v. 2, p. 99$105,2010$.

DUMAY, X.; DUPRIEZ, V. Educational quasi-markets, school effectiveness and social inequalities, Journal of Education Policy, 2013. DOI: 10.1080/02680939.2013.850536. 2013. 
DUMAY, X.; DUPRIEZ, V. ; MAROY, C. La concurrence entre écoles accroîtelle les effets de composition? Éducation comparée, [S. 1.], n. 6, p. 49-68, 2011.

DUTERCQ, Y. Que reste-t-il de l'État-éducateur?. 2006. Disponível em: <http:// matisse.univ-paris1.fr/colloque-es/pdf/articles/dutercq.pdf>. Acesso em: 4 maio 2011.

ESTÊVÃO, C. Redescobrir a Escola Privada Portuguesa como Organização. Braga: Universidade do Minho, 1998.

FELOUZIS, G.; MAROY, C. ; VAN ZANTEN, A. Les marchés scolaires: sociologie d'une politique publique d'éducation. Paris: Presses Universitaires de France, 2013.

FERNANDES, D. Avaliação em Educação: uma discussão de algumas questões críticas e desafios a enfrentar nos próximos anos. Ensaio: Avaliação e Políticas Públicas em Educação, Rio de Janeiro, n. 21, v. 78, p. 11-34, 2013.

FIGLIO, D. N.; STONE, J. A. Are private schools really better? Research in labor economics, [S. 1.], n. 35, p. 219-244, 2012.

FRIEDMAN, M. Public Schools: make them private. Education Economics, [S. 1.], n. 3, v. 5, p. 341-344, 1997.

HANUSHEK, E.; KAIN, J.; RIVKIN, S.; BRANCH, G. Charter School quality and parental decision making with school choice. Journal of Public Economics, [S. 1.], n. 91, p. 823-848, 2007.

HASSENTEUFEL, P. Chronique politique - Les groupes d'intérêt dans l'action publique: l'État en interaction. Pouvoirs, revue française d'études constitutionnelles et politiques, [S. 1.], n. 74, v. 74, p. 155-168, 1995.

HASSENTEUFEL, P. Sociologie politique: l'action publique. Paris: Armand Colin, 2008.

HATFIELD, J.W.; KOJIMA, F.; NARITA, Y. Promoting School Competition Through School Choice: a market design approach. Stanford: Stanford University Capital and Economic Opportunity Working Group Working Paper 2011-018. 2011. 
LIMA, L.; AFONSO A, Reformas da Educação Pública: Democracia, Modernização, Neoliberalismo. Porto: Edições Afrontamento, 2002.

LE GALES, P.; SCOTT, J. Une révolution bureaucratique britannique ? Autonomie sans contrôle ou, freer markets, more rules. Revue française de sociologie, [S. 1.], n. 2, v. 49, p. 301-330, 2008.

NÓVOA, A. O espaço público da educação: imagens, narrativas e dilemas. In: $A A V V$, Espaços de Educação, Tempos de Formação. Lisboa: Fundação Calouste Gulbenkian, 2002. p. 237-263.

MAGALHÃES, A. M. A nova governação e a reconfiguração das políticas educativas: entre a "competição" e a "escolha". In: VENTURA, A.; NETOMENDES, A.; COSTA, J. A. (Org.). Escolas, competição e colaboração: que perspectivas? Aveiro: Universidade de Aveiro, 2013. p. 43-56.

MAROY, C.; DEMAILLY, L. Les régulations intermédiaires des systèmes éducatifs en Europe quelles convergences? Recherches Sociologiques, [S. 1.], v. 35, n. 2, p. 5-24, 2004.

MÜLLER, K. Libre choix des écoles: libre choix de quoi et par qui? Éducation comparée, [S. 1.], n. 6, p. 29-48, 2011.

LINICK, M. A. Measuring Competition: Inconsistent definitions, inconsistent results. Education Policy Analysis Archives, [S. 1.], v. 22, n. 16, 2014.

OECD. No more failures: ten steps to equity in education. Paris: OECD, 2007.

OSBORNE, D. Uma coisa é emagrecer outra é cortar mãos e pés. Jornal Expresso. jun. 2013.

PACHECO, J. A. Políticas educativas: o neoliberalismo em educação. Porto: Porto Editora, 2000.

PEREIRA, S. Políticas de Estado e organização político-pedagógica da escola: entre o instituído e o instituinte. Ensaio: Avaliação e Políticas Públicas em Educação, Rio de Janeiro, n. 16, v. 60, p. 337-358, 2008. 
POUPEAU, F. Familles (Choix scolaires des). In: VAN ZANTEN, A. (Dir.) Dictionnaire de l'éducation. Paris: PUF, 2008. p. 398-402.

RAVITCH, D. Reign of Error: the hoax of the privatization movement and the danger to america's public schools. New York: Knopf, 2013.

. The Death and Life of the Great American School System: how testing and choice are undermining education. New York: Basic Books, 2010.

REYNAUD, J. D. Régulation de contrôle, régulation autónome, régulation conjoint. In: TERSSAC, G. (Org.). La théorie de la régulation sociale de JeanDaniel Reynaud. Paris: Éditions La Découverte, 2003. p. 103-113.

SARMENTO, M. Reinvenção do ofício de aluno. In: CANÁRIO, R.; MATOS, F.; TRINDADE, R. (Org.). Escola da Ponte - defender a escola pública. Porto: Profediçoes, 2004. p. 44- 51.

VAN ZANTEN, A.; KOSUNEN, S. School choice research in five European countries: the circulation of Stephen Ball's concepts and interpretations. London Review of Education, Londres, n. 11, v. 3, p. 239-255, 2013.

WHITTY, G.; POWER, S. A escola, o estado e o mercado: a investigação do campo actualizada. Currículo sem Fronteiras, [S. 1.], v. 2, n. 1, p. 15-40, 2002.

. Autonomia da escola e a escolha parental: direitos do consumidor versus direitos do cidadão na política educativa contemporânea. Educação, Sociedade e Culturas, [S. 1.], n. 6, p. 117-141, 1996. 


\section{Revisiting the debate on public and private in education: from the dichotomy to the complexity of public policies \\ Abstract}

The debate over public and private has an increasing role in international education agenda and in several scientific, political and social forums. This paper aims to revisit this debate, identifying current trends of policy measures that appeal to educational market. Through the eyes of policy and educational administration, the paper draws on empirical evidence to show perverse effects, particularly in educational inequalities, which resulted from centralized administration as well as from educational markets. This phenomenon is interpreted as an indicator of the complexity of public policy and, therefore, we question the advantage of maintaining a certain public/private dichotomy that tends to ignore unexpected results in collective action.

Keywords: Public and private in education. Public school. Public education policies.

\section{Revisando el debate sobre lo público y privado en la educación: de la dicotomía a la complejidad de las políticas públicas}

\section{Resumen}

El debate sobre lo público y lo privado ha adquirido creciente importancia en la agenda educativa internacional y en varios foros científicos, políticos y sociales. Este articulo pretende revisar este debate, y con ello identificar las tendencias actuales de las medidas politicas que propenden a introducir una lógica de mercado en los sistemas educativos. A través de la perspectiva de la política y la administración educacional, el texto se basa en la evidencia empírica disponible que muestra los efectos perversos, en particular en el campo de las desigualdades educativas, que son fruto de una administración centralizada, así como la introducción de los principios del mercado y la liberalización de la educación. Este fenómeno se interpreta como un indicador de la red compleja que recubren la dinámica de las políticas públicas y, en consecuencia, se cuestiona la ventaja de mantener una cierta dicotomía entre lo público y lo privado que tiende a ignorar los resultados inesperados en la acción colectiva.

Palabras clave: Lo público y lo privado en la educación. Escuela pública. Políticas públicas de educación. 